\title{
Classical order theory in the modern architectural educational process
}

\author{
Ekaterina Vozniak ${ }^{1, *}$, Yuri Kurbatov ${ }^{1}$, and Vladimir Lisovsky ${ }^{2}$ \\ ${ }^{1}$ Saint Petersburg State University of Architecture and Civil Engineering, 190005, St. Petersburg, \\ Russia \\ ${ }^{2}$ Saint Petersburg State Academic Institute for Painting, Sculpture and Architecture of the Russian \\ Academy of Arts, 199034, St. Petersburg, Russia
}

\begin{abstract}
The paper discusses the development of the theory of the classical orders of architecture in Russia in the XVIII - XIX centuries. The special significance of the works of professors of the Institute of Civil Engineers in the development of classical theory and in the education of outstanding architects is revealed. The problems and the need for teaching order theory for modern students are analyzed. The structure of the presentation of the most important concepts and techniques of classical architecture is indicated. A clear structuring of information will allow architects and restorers to freely operate a system of order architectural forms in the design.
\end{abstract}

\section{Introduction}

In the XVII - XIX centuries, the construction of buildings was carried out according to the laws of the classical order theory, which was studied in all architectural schools [1]. Classical theory has created a fairly strict and interconnected concept of the rules for constructing all the architectural details that make up the facade of the building. There were not only strict rules for drawing columns, but also a whole system for constructing the facade and its individual parts. Future architects learned these rules on the school bench, which did not negate the possibility of changing and searching for options for architectural details in further creative activity. The infinite variety of forms of different historical styles is based on an initial knowledge of the rules. Architects could freely find their way around the variety of architectural details of various styles, were able to create numerous author's variations of forms and compositionally correctly place elements on the facade and in the interior.

At the beginning of the XX century, the theory of architectural forms has been criticized, its development has stopped, and at present it is taught only in a highly condensed form in the first year of training of future architects. Typically, this course comes down to a review of the basic rules for constructing column orders and washing capital with the entablature of one of them. This leads to the fact that modern architects do not know the principles of designing historical buildings based on the classical heritage,

*Corresponding author: author@email.org 
and can only copy forms, significantly simplifying them, and often breaking the most important compositional rules. The system of teaching classical theory provided the basis for fluency in using architectural elements and formed a knowledge system for young architects, which was easy to remember and made it possible to conveniently operate information in the design process.

\section{Materials and Methods}

The classical theory is based on the treatises of M. Vitruvius, G. Vignola, L.-B. Alberti, S. Serlio, A. Palladio, V. Scamozzi and others $[2,3,4]$. By the end of the XVII century, classical theory was finally formed, and the practice of teaching it was developed in architectural educational institutions of Western Europe. An important role in this process was played by the work "The course of architecture" of F. Blondel, one of the founders of the French Royal Academy of Architecture [5].

In the XVIII century, order classical theory was perceived by Russian architects. At the Imperial Academy of Arts in St. Petersburg, young architects were taught in accordance with Italian and French works. By the end of the XIX century, studies on the theory of architectural forms appeared in Russia.

A special role in shaping one's own view of teaching the theory of architectural forms belongs to professors of the Institute of Civil Engineers. Nowadays, the Institute of Civil Engineers is called the St. Petersburg State University of Architecture and Civil Engineering. Apollinarius Kaetanovich Krasovsky (1817-1875), the founder of "rational architecture", was one of the representatives of an advanced technical school. In the mid19th century, he taught a course of classical architectural forms. A handwritten version of the lecture was preserved in the university library. A concise and at the same time succinct course taught students how to build orders and classical forms so that in the future they could move on to more complex issues of the theory of architecture, for example, the composition of buildings in general and their structures [6]. In the course, the classification of facade forms and the methods of their simplified construction are clearly identified, which later were reflected into the books of his students, N.V. Sultanov and I. B. Mikhalovsky.

The most complete and fundamental work published in Russia on this course is considered to be "The Theory of Architectural Forms" by N. V. Sultanov [7]. Nikolai Vladimirovich Sultanov (1850-1908) - a graduate, and later director of the Institute of Civil Engineers (1895-1903), ideologist and researcher of the Russian-Byzantine style, author of the Peter and Paul Cathedral in Peterhof. Among his many students are Vasily Kosyakov, architect of the Naval Cathedral in Kronstadt. In the book "The Theory of Architectural Forms", N.V. Sultanov considers only the second part of the course - the details of the façade, and does not describe column orders. All parts of the building are described in full and in detail: pedestals, cornices, horizontal and vertical rods, walls, windows, doors, balconies, etc. The book is based on an analysis of all the experience of the theory of classical architecture: from Vitruvius and Blöndel to Le Tarulha and Bulman. The book contains illustrations and an album of drawings. "Theory" was reprinted several times before the revolution and never after.

As an ideologist of the Russian-Byzantine style, Sultanov wrote a work on classical details and forms. This example shows that the theory of classical architectural forms alone does not make an architect a conservative committed to classicism. Theory provides a way to understand the construction of details and forms of the facade and in this case led to the formation of a new style.

Iosif Boleslavovich Mikhalovsky (1864-1939) graduated from the institute in 1889, having experienced, like many other students, the influence of N. V. Sultanov. For almost 
50 years, I. B. Mikhalovsky taught history and theory of architecture within the walls of the Leningrad Institute of Civil Engineering, the successor to the Institute of Civil Engineers. Back in 1905, he was confirmed as a professor, and in the 1930s, he headed the department of the history of architecture. The main theme in the scientific and pedagogical activity of Mikhalovsky was the study of classical architectural heritage. The first edition of his book "Architectural Orders" in 1916 coincided with the advent of the neoclassical style. The publication was updated and reprinted under the heading "Theory of Classical Architectural Forms" in 1925, 1935, 1937, and 1949. It survived the rise of constructivism and the advent of Socialist Classicism (Stalinist architecture) [10].

The work of I. B. Mikhalovsky bears the imprint of the 20th century. The book attempts to explain the appearance of classical architectural forms with the logic of function and construction. Unlike Sultanov, the first and most part in this book is devoted to the construction of orders. The second part, which examines the details of the facade, is a summary of the established institute course based on the book of N. V. Sultanov. The work of Mikhalovsky was the only book reprinted in the USSR, which was connected with the understanding of classical forms in the 19th century.

A study of the works of scientists from the Institute of Civil Engineers - SPSUACE showed that for three generations of professors and students who became professors, the traditions of the course of the "Theory of Architectural Forms" were supported and developed. Having such a glorious history of teaching classical architecture at SPSUACE, the successor to the Institute of Civil Engineers, professors are restoring the methodology of teaching lecture courses that give an understanding of the creation of historical architecture, both for architects and restorers. New works on this subject are published [11].

\section{Results}

In the XVIII century, teaching the theory of classical architecture took from 6 to 10 years, then at the end of the XIX century, a well-structured knowledge system already allowed mastering it in 1-2 years. Nowadays, the future architect needs to master a huge amount of knowledge, where the study of historical architecture is only one of the important components [12]. Today, when preparing architects and restorers, it is necessary to give them more extensive knowledge on the theory of architectural forms than is provided for by most curricula. Perhaps this theoretical material should be studied in the scope of the master's program, when future architects finally decided on their chosen specialization.

The overall sequence of clearly structured learning involves three steps:

1)studying profiles and orders;

2)consideration of architectural forms and details;

3)general compositional construction rules.

The study began with a consideration of the simplest elements - profiles, of which architectural forms were then composed. Then the construction of orders was studied, usually based on a treatise by G. Vignola. After the orders of G. Vignola, the orders of other architects were studied, primarily architects of the Renaissance - A. Palladio, S. Serlio, V. Scamozzi, D. Michelangelo, compared their orders with columns of Ancient Rome and descriptions of Vitruvius. This gave future architects examples of possible transformations of orders and at the same time determined the boundaries of such transformations. Since the end of the XVIII century, there was a comparative study of Greek orders at the same stage.

The next stage of teaching was to consider all the architectural details, the construction of which was based on the classical order theory. The study went in a certain sequence, all elements were divided into large groups: horizontal wall articulations; vertical wall articulations; wall elements; tops; windows; doors; balconies. 
Each group united several subgroups of parts, for example: horizontal articulations, including socles, principal and intermediate cornices, sill and secondary molding.

In turn, each subgroup (for example, socles) included several possible forms that were considered sequentially - from the simplest to the most complex, as close as possible to the order. Such structuring allowed future architects to constantly keep in mind the entire system of forms.

For example, the windows of historical buildings have a huge number of decorative options. To simplify their study, all windows were divided into two large groups:

1)windows of the main floors;

2)windows of secondary floors (basement, attic, etc.).

The windows of the main floors, which significantly differed from the others in proportions and detailing, were divided into three subgroups:

1)rectangular;

2)semicircular;

3)complex.

Each group of windows was considered in a certain sequence - from the simplest forms to the most complex ones. The complex form usually included a column order. At the same time, the construction of numerous intermediate forms of framing was studied, which are of no less interest and are often found on the facades of buildings of our cities.

Schemes for constructing semicircular windows of the main floors are presented in Fig. 1.

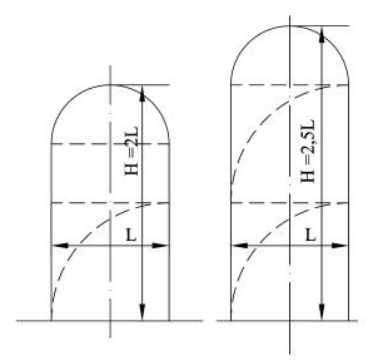

a)

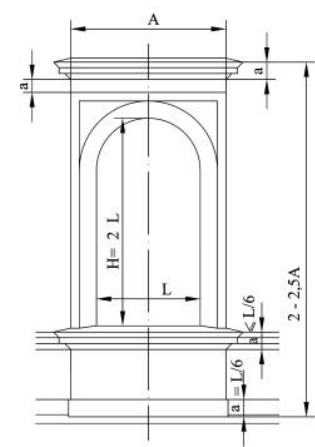

f)

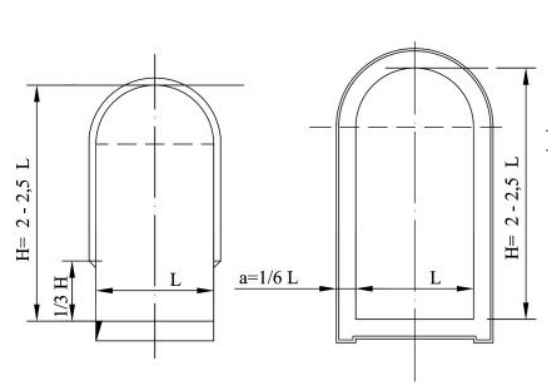

d)

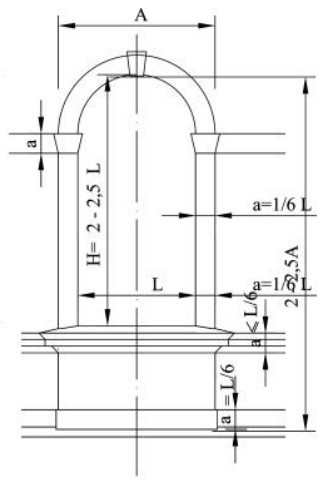

e) c)

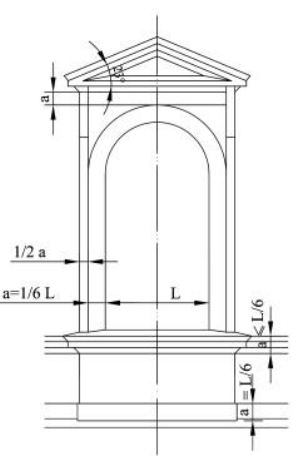

g)

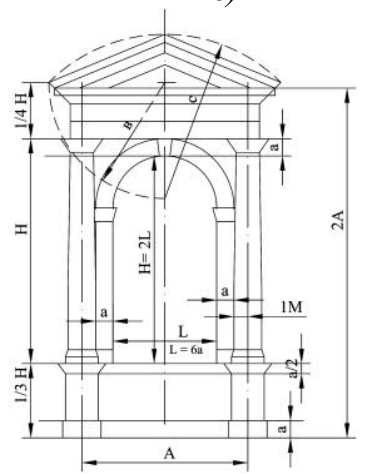

h)

a, b - classical proportions of window openings, $\mathrm{c}$ - window with chamfer, $\mathrm{d}$ - window with architrave, e - window with archivolt and window sill parapet, $\mathrm{f}$ - window with cornice, $\mathrm{g}$ - window with cornice and front, $\mathrm{h}$ - order window

Fig. 1. Classic semicircular windows. 


\section{Discussion}

In the XX century, the classical theory of architecture was replaced by a new theory of composition of forms, based on the theories of functionalism, which completely changed the approach to building architecture in general and facade details in particular [12]. The old methods of teaching classical architectural theory were gone. In the USSR, the course of classical order theory began to be reduced and gradually ceased to be taught at all. A surge of interest in this course was observed in the 1930-1950s. Nowadays, many architectural universities do not have such a course. It is still taught at some universities, but only shortened first part - the construction of a column order.

Nowadays, there is a dual world of architecture: historical architecture built in accordance with the laws of the classical order theory, and modern architecture based on the theory of functionalism. The historical part and modern buildings exist in cities in parallel. Old buildings need restoration or reconstruction. Knowledge of the theory of architectural forms is necessary in the reconstruction of historical heritage, since the combination of modern and historical architectural forms should be based on knowledge of the construction of the latter.

Some customers and architects express their commitment to the old architecture and continue to work in accordance of order theory. They are attracted to the proportionality to a man, detailing, appeal to traditions and roots. Among the trends of the newest architecture, the appeal to the old styles and the citation of order details and forms were repeatedly observed. There are two ways of architecture in the world, and future architects and restorers need to be given an idea of both theories of architecture - old one and new one.

Details, facade elements, architectural forms are an integral part of the architecture of facades and the entire building as a whole. General forms, silhouette, proportions, separation by volume - all this can be destroyed by the poor quality of drawing and execution of details. Admiring the historical buildings of St. Petersburg, one is amazed at the variety of architectural details and forms. The ability to draw elements, knowledge of the laws of their construction, creative attitude to them, the constant search and creation of new elements, the fine drawing of elements, the general skill distinguished architects of St. Petersburg of XVIII - early XX centuries [14]. Civil and church buildings, despite all the losses of subsequent years, show the skill of architects and builders. Under the influence of many factors, this skill is largely lost. Functionalism, constructivism, modernism denied the historical tradition of drawing details. The economic and political situation in Russia of the XX century also did not contribute to the quality of detailing of the facades. Textbooks and teachers who taught the execution of details to architects, artists and craftsmen are a thing of the past. Future architects, not understanding the basics of order construction, can only copy or coarsen historical samples.

\section{Conclusions}

Studying the theory of architectural forms does not in any way impede the creative abilities of the architect. A typical example of this is the experience of teaching by N.V. Sultanov. His students also worked in different directions: G.V. Baranovsky preferred modern, V.A. Kosyakov - Russian-Byzantine style. Thus, N.V. Sultanov saw in the theory of architectural forms not the oblique traditions of the past, but the necessary knowledge base that gives the architect support for free creativity in the field of architectural details. It is necessary to restore the interrupted tradition. Nowadays, it is necessary to give architects and restorers more extensive knowledge of the theory of classical architectural forms. 


\section{References}

1. Architectural theory (Köln, Taschen, 2011)

2. M. Vitruvius (Moscow, All-Union Academy of Architecture Publ. 1936)

3. G. B. Vignola (Moscow, All-Union Academy of Architecture Publ., 1939)

4. A. Palladio (London: printed for R. Ware, 1738)

5. F. Blondel http://www.e-rara.ch/zut/content/titleinfo/1287114.

6. A. Krasovskii (Parts of buildings. Saint-Petersburg, 1851)

7. N. Sultanov (Moscow, 1914)

8. Pl. Letarouilly (Paris, 1840-1857)

9. Josef. Buhlmann, ( J. Stuttgart, 1913)

10. I. B. Mikhalovskiy(All-Union Academy of Architecture Publ., 1937)

11. E. R. Voznyak (Saint-Petersburg, Colo Publ., 2015)

12. Y. I. Kurbatov (St. Petersburg: “The Art of St. Petersburg”, 2008)

13. E.K. Blinova J.Izv.RSPU, 12, 84, 44-51 (2008)

14. V.G. Lisovsky (Publishing House “Kolo” 2018) 